\title{
PENENTUAN FAKTOR KELUARAN BERKAS ELEKTRON LAPANGAN KECIL PADA PESAWAT LINEAR ACCELERATOR
}

\author{
Cahya Wulandari ${ }^{1, \mathrm{a})}$, Wahyu Edy Wibowo ${ }^{2, \mathrm{~b})}$, Supriyanto Ardjo Pawiro ${ }^{1, \mathrm{c})}$ \\ ${ }^{I}$ Departemen Fisika, FMIPA, Universitas Indonesia, Depok, 16424 \\ ${ }^{2}$ Departemen Radioterapi, RSCM, Jakarta Pusat, 1086 \\ Email: a)chaylizz.cw@gmail.com, b) wahyu.bovie@gmail.com ${ }^{\mathrm{c}}{ }^{\text {s }}$ supriyanto.p@ $@$ sci.ui.ac.id
}

\begin{abstract}
Abstrak
Berkas elektron memiliki distribusi dosis yang uniform di permukaan sehingga sering digunakan sebagai terapi kanker di permukaan tubuh. Kanker yang lokasinya dekat dengan organ sehat memerlukan terapi menggunakan lapangan yang kecil, sehingga dosimetri yang akurat untuk berkas elektron lapangan kecil menjadi suatu tantangan tersendiri. Pengukuran keluaran berkas elektron dilakukan dengan menggunakan detektor Exradin ion chamber A11 plan-paralel dan film gafchromic EBT-3 yang diletakkan pada slab solid water phantom pada kedalaman referensi (zref) dan kedalaman maksimum (zmax). Kedua detektor diradiasi dengan berkas elektron energi 6, 8, 10, 12, dan $15 \mathrm{MeV}$ pada lapangan berukuran $1 \times 1,2 \times 2,3 \times 3,5 \times 5,8 \times 8$, dan $10 \times 10 \mathrm{~cm} 2$ yang terbuat dari cerrobend. Faktor keluaran ditentukan dengan rasio perbandingan antara hasil pengukuran pada kedalaman maksimum (zmax) dan hasil pengukuran pada kedalaman referensi (zref). Hasil yang diperoleh menunjukan bahwa penurunan faktor keluaran sebanding dengan penurunan energi dan luas lapangan berkas elektron. Terdapat juga perbedaan nilai hasil keluaran kedua detektor tersebut diantaranya maksimum sebesar $78.3 \%-85.7 \%$ pada lapangan 1 X 1, dan minimum sebesar $0.15 \%-0.66 \%$ pada 8 X 8 disemua energi, sehingga detektor film gafchromic EBT-3 sanngat baik digunakan untuk pengukuran berkas elektron lapangan kecil.
\end{abstract}

Kata-kata kunci: Berkas elektron, Lapangan kecil, Faktor keluaran, ion chamber plan-paralel, Film gafchromic EBR-3

\begin{abstract}
The electron beam has a uniform dose distribution on the surface so it is often used as a cancer therapy, especially at the body surface. Cancers that are located close to organs at risk require treatment using a small field, so that accurate dosimetry for electron beam small field becomes a challenge. Output measurement performed using electron beam detector Exradin ion chamber A11 plan-parallel and gafchromic film EBT-3 placed on slab of solid water phantom at the depth of the reference (zref) and maximum depth (zmax). Both of detector is irradiated with an electron beam energy of 6, 8, 10, 12, and $15 \mathrm{MeV}$ in the field of small square shaped measuring $1 \times 1,2 \times 2,3 \times 3,5 \times 5,8 \times 8$ and $10 \times 10 \mathrm{~cm} 2$ made of cerrobend. Output factors is determined by the ratio between the measurement results at a maximum depth (zmax) and the measurement results on the reference depth (zref). The results obtained show that the decline in output factor proportional to a decrease field size and comprehensive energy electron beam. There are also differences in the value of the output of the two detectors are among a maximum of $78.3 \%-85.7 \%$ on field $1 \times 1$, and a minimum of $0.15 \%-0.66 \%$ on $8 \times 8$ in all the energy, so that the detector movie gafchromic EBT-3 sanngat well used for measurement electron beam pitch.
\end{abstract}

Keywords: Small field, Electron beam, Output factor, Exradine ion chamber A11 plan-paralel, Film gafchromic EBT-3 


\section{PENDAHULUAN}

Berkas elektron memiliki distribusi dosis yang uniform di permukaan sehingga sering digunakan sebagai terapi kanker terutama di permukaan tubuh [1]. Kanker yang lokasinya dekat dengan organ sehat memerlukan terapi menggunakan lapangan yang kecil [2], [3]. Berkas elektron lapangan kecil digunakan untuk terapi klinis pada lokasi kanker permukaan untuk elektron energi rendah. Berkas elektron energi rendah dengan diameter $\leq 3 \mathrm{~cm}$ juga telah digunakan pada terapi kanker telinga, kelopak mata, hidung, dan bibir [4], sedangkan elektron energi tinggi digunakan pada lapangan kecil yang diterapkan untuk terapi tumor tulang rusuk pada pasien gemuk, dan daerah tertentu seperti daerah dekat lensa mata dan daerah blok (blok tenggorokan) pada persimpangan dua lapangan foton [5].

TABEL 1. Faktor keluaran berkas elektron lapangan kecil dengan menggunakan Exradin ion chamber A11 planparalel dan film gafchromic EBT-3

\begin{tabular}{|c|c|c|c|c|c|}
\hline \multirow{2}{*}{$\begin{array}{l}\text { Aplikator } \\
\qquad\left(\mathrm{cm}^{2}\right)\end{array}$} & \multirow{2}{*}{$\begin{array}{c}\text { Luas } \\
\text { Lapangan } \\
\left(\mathbf{c m}^{2}\right)\end{array}$} & \multirow{2}{*}{$\begin{array}{l}\text { Energi } \\
(\mathrm{MeV})\end{array}$} & \multicolumn{2}{|c|}{ Faktor Keluaran } & \multirow[b]{2}{*}{ Deviasi } \\
\hline & & & $\begin{array}{c}\text { Exradin Ion Chamber } \\
\text { A11 Plan-Paralel }\end{array}$ & $\begin{array}{c}\text { Film Gafchromic } \\
\text { EBT-3 }\end{array}$ & \\
\hline $6 \times 6$ & $1 X 1$ & & 0.1244 & 0.8724 & $85.7 \%$ \\
\hline $6 \times 6$ & $2 \times 2$ & & 0.4717 & 0.9490 & $50.3 \%$ \\
\hline $6 \times 6$ & $3 \times 3$ & 6 & 0.6954 & 0.9783 & $28.9 \%$ \\
\hline $6 \times 6$ & $5 \times 5$ & & 0.9060 & 0.9888 & $8.37 \%$ \\
\hline $10 \times 10$ & $8 \times 8$ & & 0.9924 & 0.9990 & $0.66 \%$ \\
\hline $6 \times 6$ & $1 \mathrm{X} 1$ & & 0.1476 & 0.8802 & $83.2 \%$ \\
\hline $6 \times 6$ & $2 \times 2$ & & 0.5824 & 0.9587 & $39.2 \%$ \\
\hline $6 \times 6$ & $3 \times 3$ & 8 & 0.7719 & 0.9720 & $20.6 \%$ \\
\hline $6 \times 6$ & $5 \times 5$ & & 0.9372 & 0.9961 & $5.91 \%$ \\
\hline $10 \times 10$ & $8 \times 8$ & & 0.9916 & 0.9932 & $0.16 \%$ \\
\hline $6 \times 6$ & $1 \mathrm{X} 1$ & & 0.1653 & 0.8873 & $81.4 \%$ \\
\hline $6 \times 6$ & $2 \times 2$ & & 0.6482 & 0.9498 & $31.8 \%$ \\
\hline $6 \times 6$ & $3 \times 3$ & 10 & 0.8487 & 0.9739 & $12.9 \%$ \\
\hline $6 \times 6$ & $5 \times 5$ & & 0.9491 & 0.9965 & $4.76 \%$ \\
\hline $10 \times 10$ & $8 \times 8$ & & 0.9916 & 0.9931 & $0.15 \%$ \\
\hline $6 \times 6$ & $1 \times 1$ & & 0.1799 & 0.9209 & $80.5 \%$ \\
\hline $6 \times 6$ & $2 \times 2$ & & 0.6963 & 0.9494 & $26.7 \%$ \\
\hline $6 \times 6$ & $3 \times 3$ & 12 & 0.8905 & 0.9745 & $8.62 \%$ \\
\hline $6 \times 6$ & $5 \times 5$ & & 0.9755 & 0.9984 & $2.30 \%$ \\
\hline $10 \times 10$ & $8 \times 8$ & & 0.9916 & 0.99521 & $0.36 \%$ \\
\hline $6 \times 6$ & $1 \times 1$ & & 0.1998 & 0.9215 & $78.3 \%$ \\
\hline $6 \times 6$ & $2 \times 2$ & & 0.7453 & 0.9499 & $21.5 \%$ \\
\hline $6 \times 6$ & $3 \times 3$ & 15 & 0.9294 & 0.9772 & $4.89 \%$ \\
\hline $6 \times 6$ & $5 \times 5$ & & 0.9879 & 0.9956 & $0.06 \%$ \\
\hline $10 \times 10$ & $8 \times 8$ & & 0.9950 & 0.9920 & $0.41 \%$ \\
\hline
\end{tabular}

Dosimetri yang akurat untuk berkas elektron lapangan kecil menjadi suatu tantangan tersendiri dimana berkas elektron kecil umumnya diproduksi menggunakan lead cutout atau cerrobend. Oleh karena itu, dilakukan penelitian untuk mengetahui katakteristik dosimetri dan penentuan fakor keluaran elektron lapangan kecil.

\section{METODE PENELITIAN}

Penelitian ini dilakukan dengan menggunakan pesawat radioterapi Linnear Accelerator (Linac) Elekta Synergy Platform yang memancarkan berkas berkas foton energi 6 dan 8 MV juga berkas elektron dengan energi $6,8,10,12,15$, dan $18 \mathrm{MeV}$. Pesawat Linac tersebut dipasangi aplikator berukuran $10 \times 10 \mathrm{~cm} 2$ dan $6 \times 6 \mathrm{~cm} 2$ yang dilengkapi dengan cutout yang terbuat dari cerrobend. Cutout yang digunakan berbentuk persegi dengan variasi ukuran yaitu 1 X 1, 2 X 2, 3 X 3, 5 X 5, 8 X 8 , dan $10 \times 10 \mathrm{~cm} 2$. 
Pengukuran keluaran berkas elektron dilakukan dengan menggunakan detektor Exradin ion chamber A11 plan-paralel dan film gafchromic EBT-3 yang diletakkan pada slab solid water phantom pada kedalaman referensi (zref) dan kedalaman maksimum (zmax) yang diatur dengan SSD $100 \mathrm{~cm}$. Keluaran berkas elektron akan langsung dibaca menggunakan elektrometer Max 4000 yang terhubung dengan detektor Exradin ion chamber A11 plan-paralel, sedangkan keluaran berkas elektron dengan menggunakan film gafchromic EBT-3 dilakukan proses scan terlebih dahulu dengan menggunakan Flat-bed scanner Epson Perfection V700 kemudian pixel value dari film tersebut dibaca dengan menggunakan imageJ 1.410 .

Pengaturan penyinaran dapata dilihat pada Gambar 1 dan berikut adalah rincian metode dalam penelitian ini:

- Menentukan kedalaman referensi $\left(z_{\text {ref }}\right)$ dan pengukuran keluaran pada kedalaman referensi $\left(z_{r e f}\right)$ berkas elektron pada masing-masing detektor, lapangan, dan energi.

- Menentukan kedalaman maksimum $\left(z_{\max }\right)$ dan pengukuran keluaran pada kedalaman maksimum $\left(z_{\max }\right)$ berkas elektron pada masing-masing detektor, lapangan, dan energi.

- Menentukan faktor keluaran berkas elektron dengan membandingan antara hasil pengukuran kedalaman maksimum $\left(\mathrm{z}_{\max }\right)$ dan hasil pengukuran pada kedalaman referensi ( $\left.\mathrm{Z}_{\text {ref }}\right)$ pada masing-masing detektor, lapangan, dan energi.

\section{HASIL DAN PEMBAHASAN}

Hasil pengukuran dan penentuan faktor keluaran berkas elektron dengan menngunakan Exradin ion chamber A11 plan-paralel dan film gafchromic EBT-3 dapat dilihat pada Tabel 1. Faktor keluaran ditentukan dengan rasio perbandingan antara nilai hasil

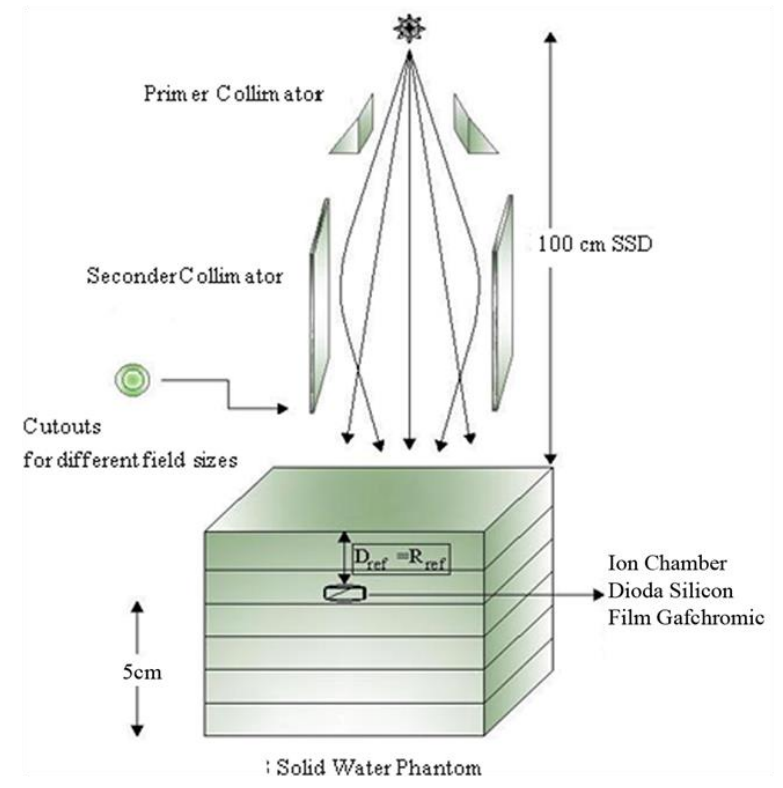

GAMBAR 1. Skema pengaturan dalam penentuan dan pengukuran keluaran pada kedalaman referensi zref dan kedalaman maksimum $\mathrm{Z}_{\max }[1]$

pengukuran pada kedalaman maksimum $\left(z_{\max }\right)$ dan nilai hasil pengukuran pada kedalaman referensi $\left(z_{\text {ref }}\right)$. Keluaran kedua detektor tersebut diukur pada kedalaman maksimum $\left(z_{\max }\right)$ yang sama yang telah diukur sebelumnya dengan menggunakan Exradin ion chamber A11 plan-paralel pada semua ukuran luas lapangan dan energi berkas elektron.

Berdasarkan pengukuran yang telah dilakukan untuk semua ukuran lapangan dan energi, faktor keluaran yang diperoleh memiliki nilai hasil yang konsisten. Perbedaan nilai hasil faktor keluaran antara detekror Exradin ion chamber A11 plan-paralel dengan film gafchromic EBT-3 yang terjadi 
dapat dilihat pada Gambar 2. Terdapat perbedaan nilai hasil kedua detektor tersebut diantaranya sebesar $78.3 \%-85.7 \%$ pada lapangan $1 \times 1,21.5 \%-50.3 \%$ pada lapangan $2 \times 2,4.89 \%-28.9 \&$ pada lapangan $3 \times 3,0.06 \%-8.37 \%$ pada lapangan $5 \times 5$, dan $0.15 \%-0.66 \%$ pada $8 \times 8$ disemua energi. Pada Gambar 3 juga terjadi penurunan faktor keluaran yang sangat drastis pada berkas elektron yang disinar pada lapangan kecil dengan menggunakan Exradin ion chamber A11 plan-paralel hingga 0.1244. Hal-hal tersebut terjadi karena detektor Exradin ion chamber A11 plan-paralel memiliki volume averaging yang lebih besar dari lapangan penyinaran yaitu $0.62 \mathrm{cc}$. Faktor keluaran pada film gafchromic EBT-3 tidak mengalami penurunan pada lapangan kecil karena film tidak dipengaruhi oleh volume averaging dan dapat mengukur berkas elektron seluas lapangan penyinaran yang diberikan.

Hasil pengukuran pada penelitian ini juga dapat ditinjau berdasarkan ukuran luas lapangan dan besarnya energi yang diberikan. Pada Tabel 1 dapat dilihat bahwa semakin kecil lapangan yang digunakan maka faktor keluaran pada kedua detektor juga akan semakin kecil. Begitupula dengan faktor keluaran yang ditinjau berdasarkan penggunaan energi dapat dilihat pada Gambar 3 yang menyatakan bahwa semakin kecil energi yang digunakan maka faktor keluarannya pun akan semakin kecil. Dengan kata lain penurunan faktor keluaran sebanding dengan penurunan lapangan dan energi berkas elektron, begitupula sebaliknya.

Faktor keluaran berkas elektron sangat dipengaruhi oleh ukuran cutout atau luas lapangan penyinaran. Ukuran lapangan (cutout) yang kecil dapat mempengaruhi berkas elektron sisi defleksi yang didominasi oleh beberapa Coulomb hamburan yang menyebabkan kurangnya keseimbangan hamburan elektron lateral (electron lateral-scatter equilibrium), sehingga terjadinya variasi keluaran mesin[3], [6]. Kurangnya keseimbangan lateral dapat terjadi lebih buruk lagi apabila dosimeter yang digunakan ukurannya lebih besar dari lapangan penyinaran, khususnya berkas elektron lapangan kecil. Pengukuran elektron pada lapangan kecil memerlukan pertimbangan khusus pada dosimeter yang akan digunakan dalam pengukurannya.

Penelitian ini juga menunjukan bahwa dosimeter film gafchromic EBT-3 memiliki nilai faktor keluaran yang stabil tanpa adanya pengaruh ketidak setimbangan elektron lateral, dibandingkan dengan Exradine ion chamber A11 plan-paralel. Film gafchromic EBT-3 dapat dinyatakan sangat baik untuk digunakan dalam pengukuran berkas elektron lapangan kecil.

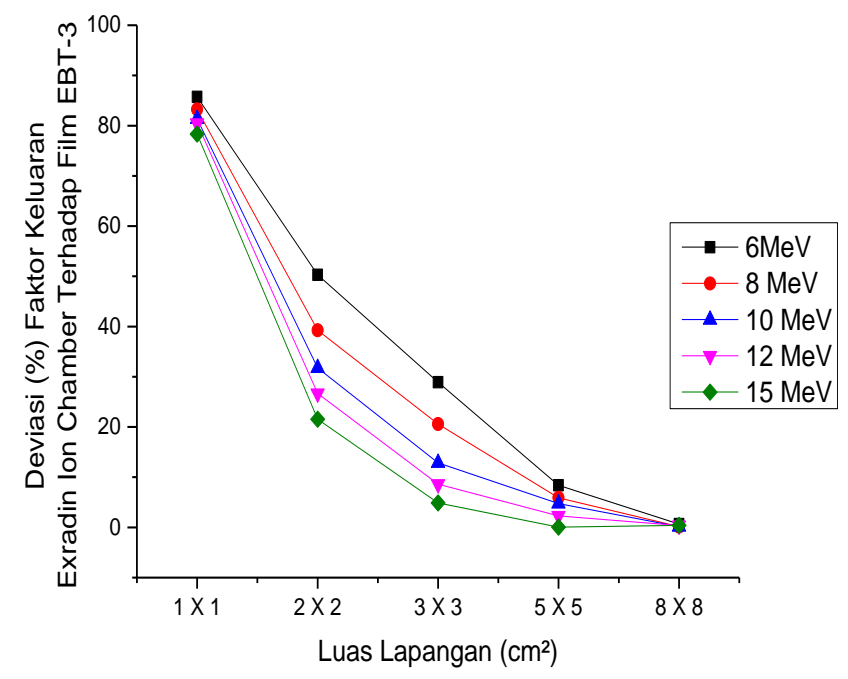

GAMBAR 2. Deviasi faktor keluaran Exradin ion chamber A11 plan-paralel terhadap film gafchromic EBT-3 

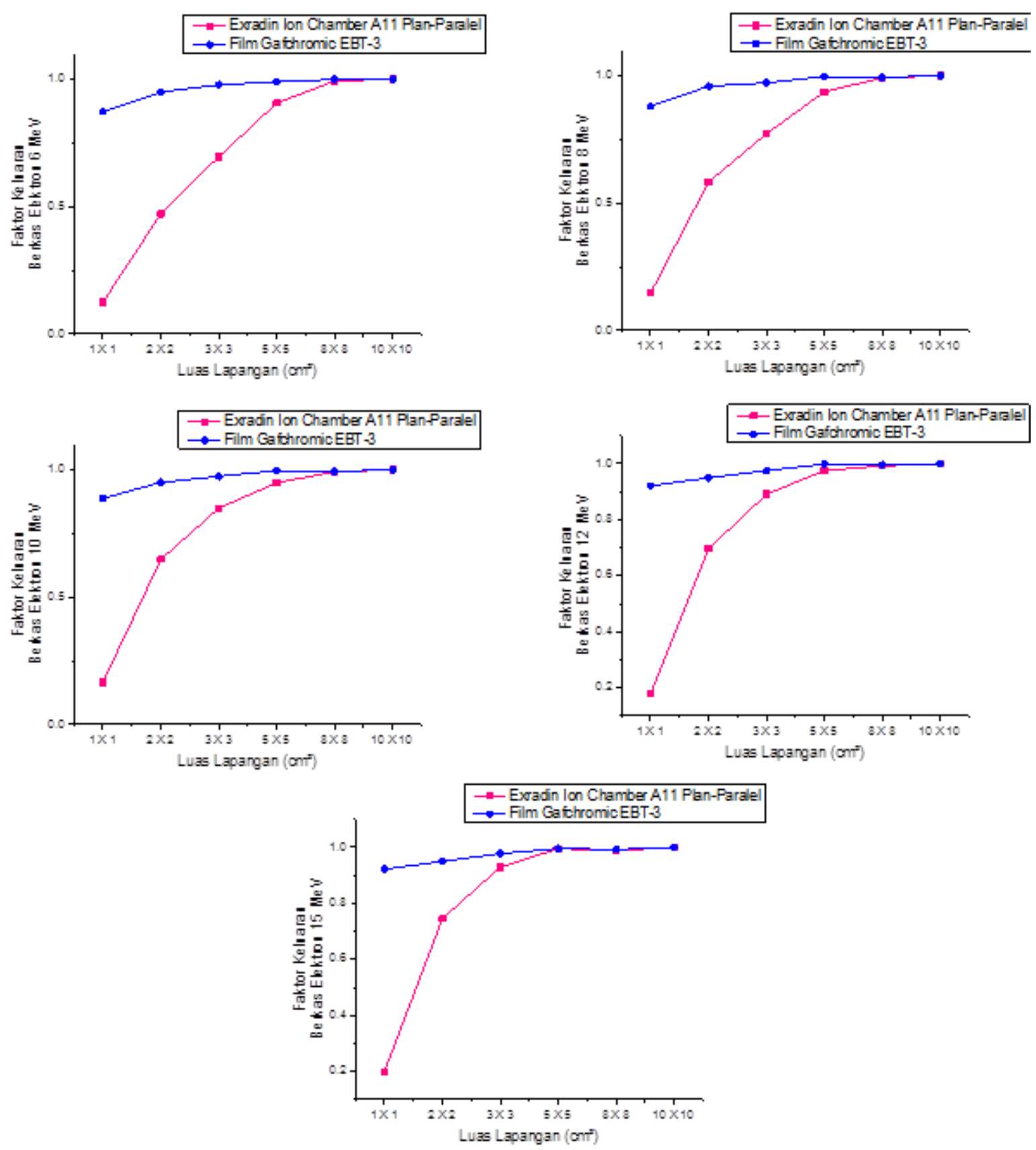

GAMBAR 3. Grafik perbandingan hasil faktor keluaran antara Exradin ion chamber A11 plan-paralel dan film gafchromic EBT-3

\section{KESIMPULAN}

Bedasarkan hasil pengukuran dan penentuan faktor keluaran berkas elektron lapangan kecil pada pesawat Linac, maka dapat disimpulkan bahwa terdapat perbedaan nilai hasil keluaran kedua detektor tersebut diantaranya maksimum sebesar $78.3 \%-85.7 \%$ pada lapangan 1 X 1 , dan minimum sebesar $0.15 \%-0.66 \%$ pada $8 \times 8$ disemua energi. Terjadi penurunan faktor keluaran yang sangat drastis pada berkas elektron yang disinar pada lapangan kecil dengan menggunakan Exradin ion chamber A11 plan-paralel hingga 0.1244. Luas lapangan yang kecil akan mempengaruhi berkas elektron sisi defleksi yang didominasi oleh beberapa Coulomb hamburan yang menyebabkan kurangnya keseimbangan hamburan elektron lateral (electron lateral-scatter equilibrium), sehingga terjadinya variasi keluaran mesin. Penurunan faktor keluaran sebanding dengan penurunan energi dan 
luas lapangan berkas elektron. Selain itu, detektor film gafchromic EBT-3 tidak dipengaruhi oleh ketidakseimbangan elektronik hamburan lateral sehingga memiliki nilai faktor keluaran yang tinggi. Pengukuran faktor keluaran menggunakan detektor film gafchromic EBT-3 dinyatakan lebih baik dibandingkan dengan Exradin ion chamber A11 plan-paralel sehingga sangat baik digunakan untuk pengukuran berkas elektron lapangan kecil.

\section{UCAPAN TERIMAKASIH}

Terimakasih kepada seluruh Fisikawan Medis dan staf Departemen Fisika Rumah Sakit Umum Pusat Dr. Cipto Mangunkusumo yang telah berkontribusi dan mendukung jalanya penelitian ini. Terimakasih kepada seluruh Dosen dan staf Laboratorium Fisika Medis Universitas Indonesia yang telah membantu dalam pengolahan data dan diskusi mengenai penelitian ini. Terimakasih juga kepada rekan-rekan seperjuangan Mahasiswa Magister Fisika Medis Universitas Indonesia angkatan 2014 yang telah membantu dan menyuport jalannya penelitian ini.

\section{DAFTAR ACUAN}

[1] N. Donmez Kesen, A. Cakir, M. Okutan, and H. Bilge, "A comparison of TPS and different measurement techniques in small-field electron beams," Med. Dosim., 2015. vol. 40, no. 1, pp. $9-15$,

[2] S. C. Sharma, M. W. Johnson, and M. S. Gossman, "Practical considerations for electron beam small field size dosimetry.," Med. Dosim., , 2005.vol. 30, no. 2, pp. 104-6.

[3] N. Amin, R. Heaton, B. Norrlinger, and M. K. Islam, "Small field electron beam dosimetry using MOSFET detector," vol. 12, no. 1, pp. 50-57P. H. Mcginley, J. R. Mclaren, and B. R. Barnett, "Small Electron Beams in Radiation Therapy 1," , 2011.pp. 231-234, 1979.

[4] S. C. Sharma, D. L. Wilson, and B. Jose, "Dosimetry of small fields for Therac 20 electron beams," 2009. vol. 697, no. 1984,

[5] M. M. X. U. Ing, A. N. I. L. S. Ethi, G. L. P. G. Lasgow, J. Fan, and E. Hospital, "Dosimetry Of Small Circular Fields For 6-Mev Electron Beams,” 2009. vol. 34, no. 1, pp. 51-56, 